\title{
REDEMOCRATIZANDO NA RAÇA: SOBRE MEMÓRIAS, INTELECTUAIS NEGROS E MOVIMENTOS SOCIAIS CONTEMPORÂNEOS (NOTAS DE PESQUISA)
}

\author{
Re-democratizing race: memories, black intellectuals \\ and contemporary social movements (research notes)
}

Sandra Martins, Togo Ioruba (Gerson Theodoro) e Flávio Gomes*

\begin{abstract}
RESUMO
Neste artigo, apresentamos uma agenda de pesquisa, sugerindo a articulação de uma história do Brasil contemporâneo com as mobilizações anti-racismo. Avaliamos uma história do tempo presente, considerando as interfaces entre mobilização, memória, intelectuais e organizações do movimento social. Com destaque para uma conexão historiográfica entre os estudos a respeito de ditadura militar, movimento estudantil e redemocratização com a mobilização antirracista das décadas de 60 e 70, com a polifonia de intelectuais negros e suas organizações. Seguindo a base teórica de estudos que conectam memória e história propomos uma abordagem sobre a formação da Sociedade Brasil África (SINBA), do Instituto de Pesquisas das Culturas Negras (IPCN), do Grupo de Trabalho André Rebouças (GTAR) e do Centro de Estudos Brasil-África (CEBA). Um dos objetivos desta pesquisa é organizar tais acervos e entender a composição deles para os antigos militantes e fundadores. Na pesquisa em andamento sobre o GTAR já localizamos a originalidade da sua constituição propondo uma pauta de reflexões na universidade brasileira desde a década de 70 .
\end{abstract}

Palavras-chave: redemocratização; movimento antirracista; movimentos sociais.

* Gerson Theodoro (também assina Togo Ioruba) é aluno do Doutorado, Sandra Martins aluna do Mestrado em História Comparada e Flávio Gomes, professor da Universidade Federal do Rio de Janeiro. 


\begin{abstract}
This paper presents aresearchagenda suggesting a link between a history of contemporary Brazil and anti-racist movements. We evaluate a history of the present, considering the interfaces between mobilization, memory, intellectuals and organizations involved in social movements. We underscore a historiographic connection between studies of the military dictatorship, the student movement and redemocratization, and the anti-racist movement of the 1960s and 70s, with a polyp hony of black intellectuals and their organizations. Following the theoretical basis for studies connecting memory and history, we propose an approach to the formation of the Brazil Africa Society (SINBA), the Institute for Studies of Black Cultures (IPCN), the André Rebouças Work Group (GTAR) and the Center for Brazil-Africa Studies (CEBA). One of the aims of this study is to organize these archives and understand their composition for former activistis and founders. In the ongoing study about the GTAR, we have already noted the originality of its constitution, proposing an agenda for reflection in Brazilian universities since the 1970s.
\end{abstract}

Keywords: redemocratization; anti-racist movement; social movements

Nestas notas de pesquisa sugerimos a articulação de uma história do Brasil contemporâneo com as mobilizações anti-racismo. Não desqualificando a longa tradição sociológica brasileira sobre pensamento social e a ideia de raça e nem desconsiderando os estudos culturalistas de uma importante geração de antropólogos, pensamos fundamentalmente numa história do tempo presente, considerando as interfaces entre mobilização, memória, intelectuais e organizações do movimento social. Nossa argumentação também destaca a necessidade de uma conexão historiográfica entre os estudos a respeito de ditadura militar, movimento estudantil e redemocratização com a mobilização antiracista das décadas de 60 e $70 .{ }^{1}$ Mais do que a polifonia de intelectuais negros e suas organizações, podemos investir sobre a produção da memória destes processos com base nos registros produzidos por organizações, entidades e grupos dos movimentos

1 MITCHELL, Michael. Racial consciousness and the political attitudes and behavior of Blacks in São Paulo, Brazil. Michigan: University of Michigan Press, 1977 e MITCHELL, Michael. Blacks and the abertura democrática. In: Fontaine, Pierre M. (ed.). Race, class and power in Brazil. Los Angeles: Center for Afro-American Studies, UCLA, 1985 
sociais da época. Com tais perspectivas avaliamos exatamente os silêncios da historiografia ao isolar tais temas. ${ }^{2}$ Antes que ensaio teórico ou resultados de uma investigação este artigo apresenta uma agenda de pesquisa em construção.

\section{Esquecidos e o pensamento ausente: a experiência da (na) reflexão}

É possível resgatar alguns intelectuais negros nos anos 70 . Ao se falar em movimento negro, nos remetemos à idéia de identidade racial. Recuperamos aqui o pensamento de Eduardo de Oliveira e Oliveira, um dos mais destacados intelectuais no alvorecer dos anos 70, que influenciaria toda uma geração com suas reflexões. Segundo ele o intelectual negro tinha uma dupla tarefa: autodescolonização/construção e produção de saberes, aplicando um pouco dos conhecimentos do branco, porém, procurando usar o conteúdo da experiência do próprio negro em cada área de atuação. Para isso, caberia tomar conhecimento e consciência de seu grupo. Saber de sua libertação social, cultural, política e econômica não seria possível sem uma teoria das condições dessa libertação. Precisaria compreender que no interior das diversas formas da ideologia dominante o conhecimento científico tinha se tornado objeto de poder. E mais: a transmissão desse mesmo conhecimento era uma apropriação de classe: burguesa ou proletária. Ou seja, vivia-se num mundo onde identidade étnica e classe social eram primordiais. É dentro deste contexto, que avaliou Oliveira, ser impossível para o intelectual negro manter uma suposta neutralidade valorativa. Argumentava como vital o surgimento de uma sociologia negra. Esta evocada como reação ao viés de uma sociologia hegemônica no então mundo acadêmico.

2 FLORES, Elio Chaves. Jacobinismo negro: lutas políticas e práticas emancipatórias (1930-1964). In: Ferreira, Jorge; Reis, Daniel Aarão. As esquerdas no Brasil. vol. 1 (A formação das tradições: 1889-1945). Rio de Janeiro: Civilização Brasileira, 2007, pp. 493-537. 
Embora nem sempre explicitadas, as idéias lançadas por Oliveira no final da década de 70 propunham um esboço na construção de novos modelos teóricos que contemplassem as experiências afrodescendentes. Os intelectuais negros deveriam ter a consciência de que os problemas e soluções em torno da questão racial, mais do que sociológicos eram de natureza política. Seria necessário entender o que significava ser negro no Brasil, entre memória, passado e expectativas de transformação. ${ }^{3}$ No lugar do discurso de vitimização do negro que o colocava na condição subalterna ou tentava humanizá-lo pelo sofrimento, Oliveira destacava na ocasião a importância de uma abordagem histórica, levando em conta os impactos da escravização e da pós-abolição. Os sentidos econômicos, culturais e sociais deveriam ser inquiridos. Ainda no início dos anos 80, outro intelectual negro (uma mulher) de grande influência chamaria a atenção para os aspectos psicológicos da exclusão racial. Para Neusa Santos o autoconhecimento que Oliveira argumentava era a necessidade de reconhecimento do estrago feito na psique do negro para "livrar-se da concepção tradicionalista que o definia econômica, política e socialmente como inferior e submisso, e não possuindo outra concepção positiva de si mesmo, ele viu-se obrigado a tomar o branco como modelo de identidade, para estrutura suas estratégias de ascensão social". ${ }^{4}$ A base hierarquizada da sociedade brasileira - com sua tradição escravista - tinha definido o lugar do negro: escravo, coisa, inferior, subalterno, negativo etc. ${ }^{5}$ Com o século XX e a modernização das relações de trabalho não

3 OLIVEIRA, Eduardo de Oliveira e. Etnia e compromisso cultural. In: Grupo Cultural André Rebouças (org.). Semana de estudos sobre a 357 contribuição do negro na formação social brasileira, 2, Niterói, UFF, 1977, pp. 22-28.

4 Interessante considerar as reflexões de outro intelectual negro desta geração: CARDOSO, Hamilton. A questão étnica e os movimentos sociais. Proposta, vol. 15, n ${ }^{\circ}$ 51, 1991, $\mathrm{p}$. 26-27 e CARDOSO, Hamilton. Limites do confronto racial e aspectos da experiência negra no Brasil - reflexões. In: Sader, Emir (org.). Movimentos sociais na transição democrática. São Paulo: Cortez, 1987.

5 Em meados da década de 90 Joel Rufino retomaria a questão em SANTOS, Joel Rufino dos. "O negro como lugar". In: Raça, Ciência e Sociedade. Marcos Chor Maio \& Ricardo Ventura Santos (organizadores). Rio de Janeiro: Editora Fiocruz/Centro Cultural Banco do Brasil, 1996 
houve necessariamente mudanças sociais. ${ }^{6}$ As formas de exclusão ganhariam seus discursos racialistas - mesmo pelo silêncio da questão racial - na explicação da modernidade do Brasil. ${ }^{7}$

É necessário recuperar as reflexões de alguns intelectuais negros e a base de um pensamento social que influenciaria as primeiras gerações que lideraram os movimentos sociais de luta antiracista no período da redemocratização. Na crítica deles - seja na dimensão sociológica ou psicológica - a população negra (seus protagonistas) alardeada sobre a sua exclusão não teria direito (qualidades/competência) a pensar em pensar. Qual seja, a sua reflexão seria desqualificada, sequer reconhecida e/ou transformada em denúncia. Legítima, aparentemente coerente, mas tão somente denúncia. Não poucas vezes estaria impotente quanto a alterar o seu cotidiano com um discurso racialista. Esta geração de intelectuais negros do período da redemocratização gastou uma energia considerável para refletir sobre a existência (e superação) da desigualdade racial e suas bases diante de uma sociedade - parte da qual produtora de pensamento social (acadêmico) hegemônico - que sequer admitia o racismo, para além do seu caráter não sistêmico. A suposta idéia da não coesão ou identidade racial era evocada. Neusa Santos destacava - uma voz quase isolada - como a suposta inexistência de barreiras de cor e de segregação racial associada à ideologia do embranquecimento eram transformados em ingredientes vitais para o desestímulo à solidariedade do negro, cuja referência de grupo de origem era sempre negativa. ${ }^{8}$

Embora nem sempre conectadas, as experiências de reflexão de alguns intelectuais negros se cruzaram com alguns movimentos sociais, mobilizações, organizações políticas no período da redemocratização. ${ }^{9}$ Além disso, muitos destes movimentos sociais

6 Ver: CUNHA, Silvio Humberto Passos da. Um retrato fiel da Bahia: sociedaderacismo-economia na transição para o trabalho livre no Reconcavo açucareiro, 1871-1902. Tese de Doutorado em Economia, Instituto de Economia, UNICAMP, 2004

7 PAIXÃO, Marcelo. A Lenda da Modernidade encantada: por uma crítica ao pensamento social brasileiro sobre relações raciais e projeto de Estado-Nação. Curitiba, Editora CRV, 2014

8 SOUZA, Neusa Santos. Tornar-se Negro. Ed. Graal. 1983, pp. 22

9 Para o debate nas décadas de 40 e 50 ver: GOMES, Flávio dos Santos. Em torno da herança: do escravo-coisa ao escravo-massa (a escravidão nos estudos de relações raciais no Brasil). In: Villas Boas, Glaucia; Maio, Marcos Chor (orgs.). Ideias de modernidade e sociologia no Brasil: 
negros - sob formas diversas e ainda pouco conhecidas -constituíram um espaço público para além do sistema de representação partidária e/ou de organizações de esquerda, parte das quais na clandestinidade. Ao tomar para si - protagonismo da ação e da reflexão -- as decisões que afetavam as suas condições de existência alargariam a própria noção de política, politizando múltiplas esferas do cotidiano ainda cristalizadas. A questão racial invadiria - não necessariamente seria chamada - a agenda da redemocratização. Embora ainda existam poucos estudos a respeito, ao lutar pela democracia no campo da vida social, onde a população trabalhadora estava diretamente vinculada - fábricas, serviços públicos, sindicatos, bairros; os movimentos sociais negros transformaram-se em novos sujeitos políticos. ${ }^{10}$ Segundo Cardoso, o diferencial entre o movimento negro e o conjunto das demais mobilizações sociais e populares que emergiram no Brasil nos anos 1970 era a história. Para a população negra, o cotidiano de opressão era determinado pela estrutura do racismo. Não bastava ter ascensão socioeconômica para não ser discriminado: o racismo institucional impunha a construção de pequenos hiatos com a probabilidade de excepcionalidades, que levava ao individualismo e a não-percepção coletiva. Em busca do coletivo, várias faces e formas de movimentos negros vão procurar na história a chave para compreender a realidade da população negra brasileira. ${ }^{11}$ Impelido pela necessidade de rejeitar

Ensaios sobre Luiz Aguiar Costa Pinto. Porto Alegre: Editora da UFRS, 1999, pp. 125-144. Os mais importantes estudos que recuperam estes movimentos sociais a partir dos anos 50 são: MOURA, Clóvis. Organizações negras. In: Singer, Paul; Brant, Vinicius Caldeira (orgs). São Paulo: o povo em movimento. Petrópolis/RJ:Vozes/CEBRAP, 1980, pp. 143-175 e NASCIMENTO, Abdias. $O$ negro revoltado. Rio de Janeiro: Paz e Terra, 1978.

10CARDOSO, Marcos. Movimento Negro em Belo Horizonte:1978-1998, Mazza Edições, 2002, p. 17. Para uma perspectiva mais ampla, ver autores como: ANDREWS, George Reid. O protesto político negro em São Paulo (1888-1988). Estudos Afro-Asiáticos, Rio de Janeiro, n 21, 1991, p. 27-48; GOMES, Flávio dos Santos. Negros e política (1888-1937). Rio de Janeiro: Jorge Zahar, 2005; HANCHARD, Michael. Orfeu e poder. Movimento negro no Rio de Janeiro e São Paulo, 1945-1988. Rio de Janeiro, EdUERJ, 2001 e SIQUEIRA, José Jorge. Entre Orfeu e Xangô, A Emergência de Uma Nova Consciência Sobre a Questão do Negro no Brasil. Rio de Janeiro. Pallas. 2006

11 CUNHA JR., Henrique. As estratégias de combate ao racismo, movimentos negros na escola, na universidade e no pensamento brasileiro. In: Munanga, Kabengele (org.). Estratégias e políticas de combate à discriminação racial. São Paulo: Edusp. 1996; GONÇALVES, Luiz Alberto de Oliveira. Os movimentos negros no Brasil: construindo atores sociopolíticos. Revista Brasileira de Educação, no 9, 1998; JESUS, Ilma Fátima de. O pensamento do MNU - Movimento Negro 
a história oficial na construção de uma nova interpretação da sua trajetória, é que o movimento negro distinguiu-se dos demais movimentos sociais e populares. ${ }^{12}$

\section{GTAR E O COMEÇO DO INÍCIO: ENTRE SONS E VOZES}

Em meados dos nos 70, as reflexões de Eduardo de Oliveira e Oliveira e de Beatriz Nascimento - historiadora e destacada intelectual negra da sua geração -- embasariam a criação do Grupo de Trabalho André Rebouças (GTAR): a preocupação de jovens intelectuais afrodescendentes de proporem - no interior da Universidade pública -- a formação de grupo de estudo voltado para as questões relativas ao negro no Brasil, dentro de uma abordagem das relações raciais. $\mathrm{Na}$ ocasião, tal grupo -- junto com outras entidades dos movimentos negros - começaria a por em prática a produção de uma "sociologia negra para a afirmação da identidade racial e do grupo no cenário político-cultural brasileiro", para a transformação da realidade da sociedade brasileira. ${ }^{13}$

Unificado. In: Barbosa, Lúcia M. de A.; Silva, Petronilha B. G. e (orgs.). O pensamento negro em
educação no Brasil: expressões do movimento negro. São Carlos, SP: Ed. da UFSCar. 1997;
KOSSLING, Karin Sant'Anna. As lutas anti-racistas de afro-descendentes sob vigilância do
DEOPS/SP (1964-1983). Dissertação (Mestrado). Universidade de São Paulo. Faculdade de
Filosofia. Letras e Ciências Humanas, 2007; LOPES, Maria Aparecida de Oliveira.. História e
memória do negro em São Paulo: efemérides, símbolos e identidade (1945-1978). Tese de
Doutorado. Universidade Estadual Paulista. Faculdade de Ciências e Letras de Assis, 2007;
NASCIMENTO, Maria Ercília do. A estratégia da desigualdade: o movimento negro nos anos 70 .
São Paulo: PUC-SP. 1989; PEREIRA. Amilcar Araujo. O Mundo Negro, Relaçós raciais e a
constituição do movimento negro contemporâneo no Brasil. Rio de Janeiro. Pallas: Faperj. 2013 ;
PINTO, Regina P. O movimento negro em São Paulo: luta e identidade. Tese (doutorado em
Antropologia). São Paulo:USP. $1993 ;$ SILVA, J. C. da. Histórias de lutas negras: memórias do
surgimento do movimento negro na Bahia. In: Reis, João J. Reis, (ed.). Escravidão e invenção da
liberdade. Estudos sobre o negro no Brasil. São Paulo: Brasiliense. 1988 e SILVA, Jônatas C. da.
História de lutas negras: memórias do surgimento do movimento negro na Bahia. In: Movimento
Negro Unificado. 1978-1988. 10 anos de lutas contra o racismo. São Paulo: Confraria do Livro.
1988. 12 CARDOSO, Marcos. Movimento Negro em Belo Horizonte: 1978-1998. Mazza Edições. 2002, pp. 14

13 OLIVEIRA, Eduardo de Oliveira e. pp. 26 
As memórias sobre tal cenário, impasses, organizações e expectativas oferecem um rico painel sobre uma face ainda pouco conhecida da redemocratização. Recuperam-se as experiências de mobilização de universitários cariocas nas décadas de 70 e 80 considerando o GTAR (Grupo de Trabalhos André Rebouças), coletivo criado na Universidade Federal Fluminense (UFF). ̇̀ possível analisar o protagonismo de uma geração ao fomentar reflexões sobre a questão do racismo no interior da universidade. Através de seminários e publicações, o GTAR foi uma organização pioneira de intervenção acadêmica e intelectual. Criado em 1975, por jovens negros de diversos cursos de graduação da UFF, o GTAR conquistaria um original espaço para estudos, debate público e mobilização. Ao analisar a experiência desta desconhecida intelectualidade e suas organizações, por meio dos depoimentos dos seus fundadores, ativistas, simpatizantes e outros tantos contemporâneos recupera-se inicialmente a sua própria memória a partir da documentação da sua institucionalização (atas, relatórios, eventos, fotografias, boletins).

$\mathrm{Na}$ memória resgatada entre depoimentos, entrevistas e outros registros mergulhamos nos anos 70 . Uma pequena geração de negros e negras adentrava a universidade entre olhares da invisilidade. A inquietude da juventude da época tinha pautas próprias, que ainda precisamos conhecer mais. Na UFF em fins de 1972, começaram então alguns encontros de estudantes negros. No início, um pouco mais de uma dezena de alunos, gradativamente o número foi aumentando. Por meio de dinâmica de grupo, os jovens discutiam a questão racial e a história do negro no Brasil com apoio de textos. Ao longo da semana, alguns textos eram preparados para serem discutidos na semana seguinte. Há indicações ali da leitura de livro de Abdias do Nascimento, de Clovis Moura e de questões relativas ao protesto escravo, assim como o texto de Frantz Fanon (Os Condenados da Terra) e sobre movimentos de libertação de povos africanos. Em parte eram temas proibidos no debate público da 
ocasião, sem falar de livros e informações censuradas devido a repressão do regime militar brasileiro. ${ }^{14}$

A nomeação do grupo como GTAR surgiu da necessidade de se organizarem juridicamente em consequiência do reconhecimento pelo Ministério da Educação e Cultura da IV Semana de Estudos sobre a Contribuição do Negro na Sociedade Brasileira, em 12 de setembro de 1978. Nasceria assim, o Grupo de Trabalhos André Rebouças (GTAR): sociedade civil sem finalidade lucrativa; de duração indeterminada; incorporando intelectuais, ex-alunos da UFF e alunos negros que participavam das Semanas de Estudos. Conforme determinado em seu estatuto, o GTAR passou a ser composto por Diretoria, Conselho Diretor Permanente e Assembléia Geral.

\begin{abstract}
"Era mais importante para nós, universitários, o nome de André Pinto Rebouças, do que o de Luiz Gama. Por mostrar que apesar da escravidão e preconceito e do diminuto quantitativo, o negro chegou a ser doutor. Para desmistificar os que as pessoas falavam que negro não podia ser doutor, isso em 1975. Falam até hoje que negro não pode ser doutor. O GTAR vira Grupo de Trabalho André Rebouças porque é uma forma de você maquiar o caráter político. Porque não podia colocar outro nome, era o nome que nós conseguimos furar a malha da repressão".
\end{abstract}

Através da "Semana de Estudos" e diversas outras atividades, o GTAR foi procurando atuar junto à comunidade negra na sua conscientização, para que finalmente se resgate uma dívida histórica que a sociedade brasileira tem para com o elemento afro-brasileiro. ${ }^{15}$

Mas outros cenários de influência e reflexão surgiriam. Com destaque ocorreriam as semanas afro-brasileiras, no Museu de Arte Moderna do Rio de Janeiro, em 1974, organizadas pela recém-criada

14 MONTEIRO, Helene. O ressurgimento do Movimento Negro no Rio de Janeiro na década de 70. Dissertação de Mestrado na UFRJ. Rio de Janeiro. 1991, pp. 55

15 Boletim do GTAR, novembro de 1985, Ano IV 
Sociedade de Estudos da Cultura Negra da Bahia (SECNEB). Na ocasião o surgimento do CEAA (Centro de Estudos Afro-Asiáticos da Universidade Candido Mendes) serviria como influência e posteriormente conexão de personagens, ativistas e pensamentos. Logo se transformaria num importante espaço de difusão de informações que aliada a outras fontes (de lazer, familiar e religioso) vieram a possibilitar a construção de novos saberes cujo objetivo era o estudo do negro na sociedade brasileira. Durante alguns anos, o CEAA desempenhou um papel importante na formação teórica sobre a questão africana e a sua conseqüente articulação com as relações raciais brasileira, principalmente quanto a bibliografia disponível. ${ }^{16}$ Aqueles primeiros encontros, para muitos, tiveram uma função de autoconhecimento, tanto para pesquisadores e universitários, como para estudantes secundaristas, pois, ao mesmo tempo em que possibilitava uma compreensão de como atuava a discriminação racial, era igualmente um espaço para expressarem suas expectativas sobre o tema. Para Sebastião Soares, na ocasião estudante secundarista, essas concepções são cristalinas:

Eu considero que ali era uma efervescência de jovens de discutir os rumos até da própria vida, no que diz respeito ao que era você ser negro no Brasil. Eu, desde 1972, ia participar de algumas discussões, ora no Afro-Asiático, na Praça XV ou em Ipanema, e também em algumas rodas de conversas na Adega Pérola, em Copacabana. Então lá a gente via um grupo de negros que fizeram contraste no Rio de Janeiro. Aquele período foi uma efervescência de jovens para discutir os rumos até da própria vida, no que diz respeito ao que era você ser negro no Brasil. Quando eu entrei na Universidade já conhecia de vista Romão, a Ana e a Marlene, nos vemos em algumas reuniões lá em 1973, 1974 em Ipanema. Discutíamos a reorganização do movimento negro no Brasil. O Rio de Janeiro foi um dos primeiros estados a discutir isso. Eu só conhecia as pessoas de vista, porque

16 SANTOS, Paulo Roberto dos. Instituições Afro-brasileiras, a prática de uma contemporaneidade. Centro de Estudos Afro-Asiáticos, Rio de Janeiro, mimeo., 1984 
só encontrava as pessoas esporadicamente, em 1973, 1974. ${ }^{17}$

Paradoxalmente a face mais visível da juventude negra carioca da época - com bailes reunindo milhares de pessoas - era o movimento soul, influência da cultura musical dos negros dos Estados Unidos. As músicas de cantores como James Brown, Diana Ross, Marvin Gaye, Billy Paul e outros; além de roupas, penteados e postura que exaltavam imagens positivas da estética negra, carregando uma mensagem de negros para os negros. Ainda sabemos pouco sobre a atmosfera e canais de conscientização política nestes espaços de bailes na periferia do Rio de Janeiro. O certo é que o movimento soul articula-se em algum momento com alguns setores e atividades do movimento negro.

Ao mesmo tempo várias organizações negras seriam criadas no Rio de Janeiro. A primeira entidade a ser criada, em 1974, no Rio de Janeiro foi a Sociedade Brasil África (SINBA). Com um discurso radical, eles enfatizavam a solidariedade com os povos africanos e a luta pela movimentação político-ideológica da massa da população afro-descendente com aproximação direta com as classes populares. O Instituto de Pesquisas das Culturas Negras (IPCN), formado, em 1975, por profissionais liberais, moradores da Zona Sul, tinha como objetivo difuso de desenvolver pesquisas sobre as culturas negras, no Brasil e na África, para que pudesse servir de instrumento à luta de libertação. ${ }^{18} \mathrm{O}$ relacionamento entre o IPCN e o SINBA foi intenso, tendo alguns ativistas deste último integrado a direção do Instituto. Entre suas atividades constam palestras em circuito itinerante, uma das quais serviu de inspiração para a criação do Centro de Estudos Brasil-África (CEBA), no município de São Gonçalo, em 1976.

17 Entrevista realizada para esta pesquisa com Sebastião Soares um dos fundadores do Grupo de Trabalhos André Rebouças (GTAR)

18 Dois importantes intelectuais refletiram a respeito em seus ensaios clássicos: GONZÁLES, Lélia. O Movimento Negro na última década. In: Gonzáles, Lélia; Hasenbalg, Carlos (orgs.). O lugar do negro. Rio de Janeiro: Marco Zero. 1980.; SANTOS, Joel Rufino dos. $O$ movimento negro e a crise brasileira. Política \& Administração. Rio de Janeiro, $\mathrm{n}^{\circ} 2$, jul./set., 1985 e SANTOS, Joel Rufino dos. IPCN e Cacique de Ramos. Comunicações do ISER, ano 7, n. 28, Rio de Janeiro, ISER, 1988, PP. 5-20 


\section{Das memórias e legados dos movimentos sociais: uma agenda de pesquisa}

Com perspectivas de recuperar cenários, paisagens, personagens e memórias da mobilização antiracista entre os fins da década de 60 até o início dos anos 80 propusemos ao CNPq (Edital Ciências Humanas/2014) um projeto visando um levantamento sobre a mobilização política e as associações (entidades, grupos, coletivos) e os documentos periódicos - jornais, revistas e boletins - produzidos pela e dirigidos à população negra como veículos de denúncia, educação e formação de opinião acerca do debate sobre a questão racial no Brasil. Tal investigação deverá ter um esforço para um mapeamento e a digitalização de acervos pessoais visando à disponibilização numa plataforma (on-line) acerca dos intelectuais negros, associações, entidades e periódicos na década de 70 . O resultado desta pesquisa pode significar mais um esforço no sentido de fomentar e instrumentalizar, tanto temática quanto materialmente, pesquisas sobre a população negra contemporânea e suas formas de organização políticas e culturais. Um dos principais objetivos da pesquisa é tornar viável diversas abordagens sobre a memória social destas entidades e seus principais articuladores (investigações baseadas na recuperação de coleções particulares de intelectuais e militantes negros) de forma a construir a base inicial de um acervo sobre a história e a memória da mobilização negra no Brasil contemporâneo.

Em termos historiográfico há uma quase total silêncio sobre esta dimensão do período de redemocratização pois o surgimento de um movimento social de caráter étnico-racial na década de 70 parece não ter tido o mesmo grau de repercussão de outras mobilizações sociais que ameaçavam o regime militar, em fase de abertura política. O governo militar e mesmo a sociedade civil não viam, com perigo ou com seriedade, que a aglutinação de jovens negros - embalados pela Black Music - tivesse algum conteúdo político-ideológico de caráter transformador. Dessa forma, torna-se bastante curioso como um grupo de estudantes conseguiria se reunir numa universidade federal 
da capital do antigo Estado do Rio de Janeiro para discutir o paradoxo da diferenciação racial? ${ }^{19}$

Em termos teóricos e metodológicos pretende-se investir nas conexões entre memória coletiva e identidades. Seguindo a base teórica de estudos que conectam memória e história oral propomos uma abordagem sobre a formação do IPCN, SINBA, CEBA e GTAR, a reconstrução/reconstituição que seus fundadores fazem da memória, considerando cenários, personagens e ações. Com base em acervos pessoais, fotografias e memória dos seus protagonistas queremos recuperar uma face da história de alguns movimentos sociais durante a ditadura e no período da redemocratização, considerando a memória, o pensamento e a experiência da mobilização da luta antirracista no Brasil contemporâneo. ${ }^{20}$ Em termos de roteiro de investigação estamos considerando a rica e original documentação produzida pelas próprias organizações, o que equivale às atas, boletins, publicações, folders, áudio de programas de rádio, etc. Também no CIEC da UFRJ há um acervo com depoimentos e panfletos de organizações negras e depoimentos organizados por Márcia Contins. ${ }^{21}$ No CPDOC/FGV há disponível um banco de depoimentos sobre movimento negro coletados em base audiovisual por Amílcar Pereira e Verena Alberti. ${ }^{22}$ Há ainda materiais guardados com integrantes do IPCN, SINBA, CEBA e GTAR, de forma dispersa.

19 D’ADESKY,Jacques. Pluralismo Étnico e Multiculturalismo: racismos $e$ antiracismos no Brasil, Rio de Janeiro, Pallas, 2001, p. 139.

20 Ver entre outros: ANDREWS, George Reid. O protesto político negro em São Paulo (1888-1988). Estudos Afro-Asiáticos, Rio de Janeiro, n 21, 1991, p. 27-48; BAIRROS, Luíza. Orfeu e Poder: uma perspectiva afro-americana sobre a política racial no Brasil. Salvador, AfroÁsia, no 17, p. 173-186, 1996; CUNHA, Olívia Maria Gomes da. Depois da festa. Movimentos negros e 'políticas de identidade' no Brasil. In: Alvarez, Sonia E.;Dagnino, Evelina; e Escobar, Arturo (orgs.). Cultura e Política nos movimentos sociais latino-americanos. Novas Leituras. Belo Horizonte: Ed. UFMG, 2000, p. 333-380; DOMINGUES, Petrônio. Movimento negro brasileiro: alguns apontamentos históricos. Tempo 23.12 (1999) http:/www.scielo.br/pdf/tem/v12n23/v12n23a07.pdf; GOMES, Flávio dos Santos. Negros e política (1888-1937). Rio de Janeiro: Jorge Zahar, 2005; HANCHARD, Michael. Orfeu e poder. Movimento negro no Rio de Janeiro e São Paulo, 19451988. Rio de Janeiro, EdUERJ, 2001 e SIQUEIRA, José Jorge. Entre Orfeu e Xangô, A Emergência de Uma Nova Consciência Sobre a Questão do Negro no Brasil. Rio de Janeiro. Pallas. 2006

21 CONTINS, Marcia. Lideranças Negras. Rio de Janeiro: Aeroplano. 2005

22 ALBERTI. Verena \& PEREIRA, Amilcar Araujo. Histórias do movimento negro no Brasil: depoimentos ao CPDOC - Rio de Janeiro: Pallas; CPDOC-FGV, 2007 
Um dos objetivos desta pesquisa em andamento é organizar tais acervos e entender a composição deles para os antigos militantes e fundadores. A propósito, os dois principais intelectuais negros - já falecidos - que deram suporte ao GTAR tiveram os seus acervos particulares depositados em instituições públicas. A historiadora Beatriz Nascimento teve seu acervo doado para o Arquivo Nacional, onde se encontra tratado e com instrumento de pesquisa de acesso ao público. Na Universidade Federal de São Carlos temos o acervo pessoal do cientista social Eduardo de Oliveira e Oliveira, considerado um dos mais importantes intelectuais acadêmicos do movimento negro. Pretendemos também acompanhar o debate sobre relações raciais e mobilização política nos jornais da década de 70 . É possível acompanhar notícias envolvendo a mobilização estudantil e o debate em torno de eventos e organizações negras, principalmente na década de 70. No Arquivo Nacional e no Arquivo Público do Estado do Rio de Janeiro, pretendemos trabalhar com as fontes da repressão e polícia política (DEOPS) durante a ditadura. Tem sido possível acessar os dossiês e prontuários de militantes e organizações e ver como os órgãos de repressão avaliavam a mobilização racial e seus integrantes.

$* * * * * * * * *$

Na primeira fase da pesquisa focando na reconstituição da trajetória do GTAR e seus intelectuais tem sido utilizada a história oral e as reflexões teórica sobre memória. ${ }^{23} \mathrm{O}$ maior interesse tem sido recuperar as versões daqueles que participaram ou testemunharam a trajetória da entidade. A análise destas "memórias" tem propiciado um entendimento sobre o relacionamento entre os setores acadêmicos e estes estudantes negros, que buscavam a reformulação do ponto de vista conceitual de uma nova teoria das

23 AMADO, Janaina e FERREIRA, Marieta de Moraes. (Coordenadoras) Usos \& abusos da história oral. Rio de Janeiro: FGV. 1996. 
relações raciais no Brasil. ${ }^{24} \mathrm{O}$ conjunto de documentos produzidos pela organização e a bibliografia sobre Movimento Negro serviram de apoio para a investigação e de instrumento de análise das entrevistas. Os depoentes foram escolhidos em função de sua importância nas fases transitórias dos dois momentos a serem privilegiados, - a fundação do grupo, em 1975 e a paralisação das atividades, em 1995. A primeira fase se dará nos anos 70 com início das discussões na universidade e pesquisa acadêmica; a segunda, ao longo dos anos 80 , envolvendo atividades de extensão. E anos 90, ainda conservando o referencial acadêmico, o grupo se volta para uma militância externa ao campus universitário.

Várias organizações sociais como IPCN, SINBA, CEBA e mais ainda o GTAR podem ter desempenhado várias funções pedagógicas na conjuntura dos anos 70 e início dos anos $80 .^{25}$ De um lado, no permanente movimento de construção identitária para os integrantes destes grupos. Ao mesmo tempo foi fundamental na disseminação das informações e arregimentação de interlocutores sociais, em termos pessoais, coletivos, públicos e privados. Numa agenda de pesquisa em construção abordamos a memória social destes grupos, suas fundações, seus personagens, ações e expectativas, além do diálogo com setores sociais dentro e fora da universidade. Como se constituíram estes grupos? Quais as suas perspectivas? Como dialogoram entre si e com outros movimentos e setores envolventes? Quais os intelectuais que influenciaram suas ações e abordagens? Quais as estratégias de organização, discussão e divulgação das suas ações? Quais eram os intelectuais acadêmicos com quem dialogaram? No caso do GTAR é possível considerá-lo como pioneiro na formação de um coletivo de ação e reflexão que, em muito, antecede o surgimento dos NEABs (Núcleos de Estudos Afrobrasileiros) nas universidades públicas e, mais ainda, com o advento

24 Uma memória que recupera as conexões e expectativas das organizações negras, seus intelectuais e a pesquisa acadêmica nos anos 40 e 50, ver: LEITE, José Correia. E disse o velho militante José Correia Leite: depoimentos e artigos. Organização e textos de Cuti. São Paulo: Secretaria Municipal de Cultura. 1992. Ver ainda: BARBOSA, Márcio. Frente Negra Brasileira: depoimentos. Organizador Quilombhoje. São Paulo. Quilombhoje, 1998

25 Uma memória aparece também em: BERRIEL, Maria Maia de Oliveira. A Identidade Fragmentada: As muitas maneiras de ser negro. Tese de doutoramento pela USP. Mimeografado. São Paulo. 1988 
da Lei 10.639 e seus desdobramentos em diversas áreas acadêmicas e aquelas de ciências sociais aplicadas de ensino e pesquisa. ${ }^{26}$ Reconhece-se assim os movimentos sociais no período que antecede a redemocratização e a articulação deles (e suas temáticas) com a universidade pública. O GTAR foi original na proposição de um debate na universidade, organizado pelos próprios estudantes negros. Destaca-se a autonomia e agenda própria, a despeito do movimento estudantil, dos grupos de esquerda e da atmosfera da ditadura e repressão. ${ }^{27} \mathrm{~A}$ organização do GTAR se destacaria na promoção de eventos no espaço universitário, especialmente com semanas de estudos, seminários e publicações.

\author{
RECEBIDO EM: 02/01/2016 \\ APROVADO EM: 19/04/2016
}

26 SANTOS, Sales Augusto dos. A Lei $n^{\circ} 10.639 / 03$ como fruto da luta anti-racista do Movimento Negro. In: Educação anti-racista: caminhos abertos pela Lei Federal $\mathrm{n}^{\circ} 10.639 / 03$. Brasília: MEC-SECAD. 2005.

27 FICO, Carlos. Além do golpe: versões e controvérsias sobre 1964 e a ditadura militar. 3. ed. Rio de Janeiro: Record, 2014; Como eles agiam. Os subterrâneos da Ditadura Militar: espionagem e polícia política. Rio de Janeiro: Record, 2001 e Reinventando o otimismo: ditadura, propaganda e imaginário social no Brasil (1969-1977). Rio de Janeiro: Editora Fundação Getúlio Vargas, 1997; FILHO. Daniel Aarão Reis. Ditadura e Democracia no Brasil: do golpe de 64 a constituição de 88, Rio de Janeiro: Zahar. 2014 e FILHO. Daniel Aarão Reis; RIDENTI, Marcelo; MOTTA, Rodrigo Patto. O Golpe e a Ditadura Militar 40 anos depois (1964 - 2004), Bauru, São Paulo: Edusc. 2004. 